\title{
Geographic potential of the world's largest hornet, Vespa mandarinia Smith (Hymenoptera: Vespidae), worldwide and particularly in North America
}

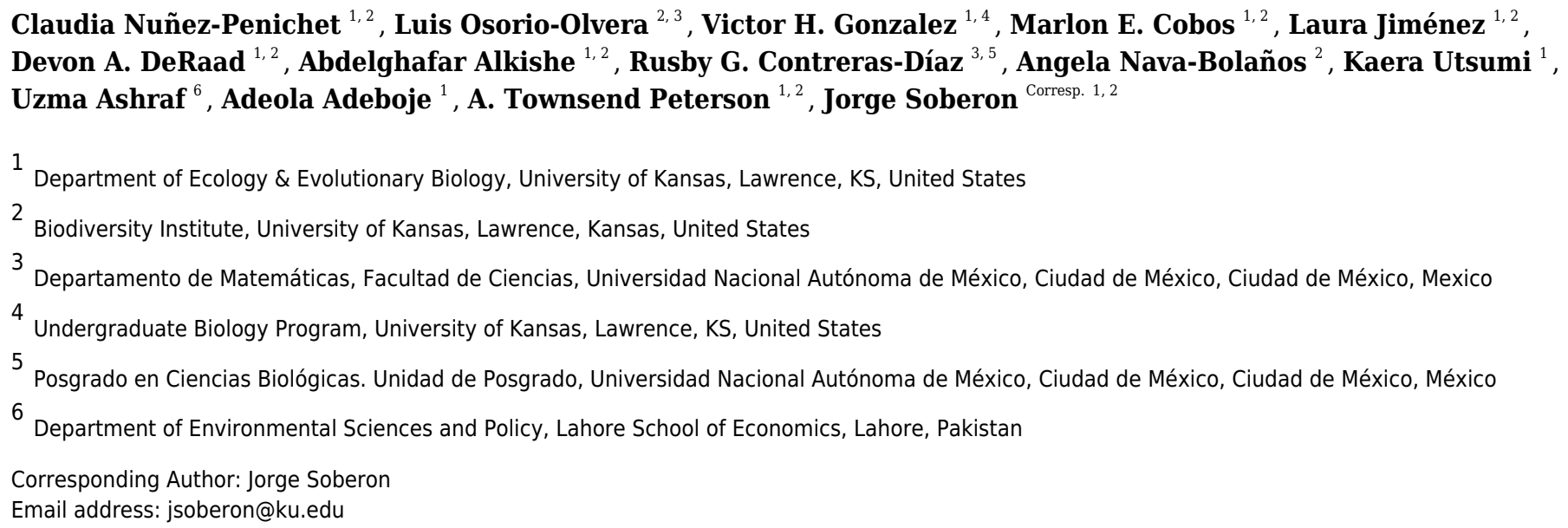

The Asian giant hornet (AGH, Vespa mandarinia) is the world's largest hornet, occurring naturally in the Indomalayan region, where it is a voracious predator of pollinating insects including honey bees. In September 2019, a nest of Asian giant hornets was detected outside of Vancouver, British Columbia, multiple individuals were detected in British Columbia and Washington state in 2020, and another nest was found and eradicated in Washington state in November 2020, indicating that the AGH could have successfully wintered in North America. Because hornets tend to spread rapidly and become pests, reliable estimates of the potential invasive range of $V$. mandarinia in North America are needed to assess likely human and economic impacts, and to guide future eradication attempts. Here, we assess climatic suitability for AGH in North America, and suggest that, without control, this species could establish populations across the Pacific Northwest and much of eastern North America. Predicted suitable areas for AGH in North America overlap broadly with areas where honey production is highest, as well as with species-rich areas for native bumble bees and stingless bees of the genus Melipona in Mexico, highlighting the economic and environmental necessity of controlling this nascent invasion. 
1 Geographic potential of the world's largest hornet, Vespa mandarinia Smith

2 (Hymenoptera: Vespidae), worldwide and particularly in North America

3 Claudia Nuñez-Penichet ${ }^{1,2}$, Luis Osorio-Olvera ${ }^{2,3}$, Victor H. Gonzalez ${ }^{1,4}$, Marlon E. Cobos ${ }^{1,2}$,

4 Laura Jiménez $^{1,2}$, Devon A. DeRaad ${ }^{1,2}$, Abdelghafar Alkishe ${ }^{1,2}$, Rusby G. Contreras-Díaz ${ }^{3,5}$,

5 Angela Nava-Bolaños ${ }^{2}$, Kaera Utsumi $^{1}$, Uzma Ashraf ${ }^{6}$, Adeola Adeboje ${ }^{1}$, A. Townsend

6 Peterson $^{1,2}$, Jorge Soberon ${ }^{1,2 *}$

$7 \quad{ }^{1}$ Department of Ecology \& Evolutionary Biology, University of Kansas, Lawrence, KS, USA.

$8 \quad$ 2Biodiversity Institute, University of Kansas, Lawrence, KS, USA.

9 32Departamento de Matemáticas, Facultad de Ciencias, Universidad Nacional Autónoma de

10 México, Ciudad de México, Ciudad de México, México.

$11{ }^{4}$ Undergraduate Biology Program, University of Kansas, Lawrence, KS, USA.

12 5Posgrado en Ciencias Biológicas. Unidad de Posgrado, Universidad Nacional Autónoma de

13 México, Ciudad de México, Ciudad de México, México.

$14{ }^{6}$ Department of Environmental Sciences and Policy, Lahore School of Economics, Lahore, 15 Pakistan.

17 *Corresponding Author: Jorge Soberon

18 Department of Ecology \& Evolutionary Biology and Biodiversity Institute, University of Kansas, 191345 Jayhawk Blvd., Lawrence, Kansas 66045, USA. jsoberon@ku.edu 
20

\section{ORCID:}

22 CNP: https://orcid.org/0000-0001-7442-8593

23 LOO: https://orcid.org/0000-0003-0701-5398

24 VHG: https://orcid.org/0000-0002-4146-1634

25 MEC: $\underline{\text { https://orcid.org/0000-0002-2611-1767 }}$

26 LJ: https://orcid.org/0000-0002-6683-9576

27 DAD: https://orcid.org/0000-0003-3105-985X

28 AbA: https://orcid.org/0000-0003-2927-514X

29 RGCD: https://orcid.org/0000-0002-0569-8984

30 ANB: $\underline{\text { https://orcid.org/0000-0002-4371-5415 }}$

31 KU: https://orcid.org/0000-0001-5935-7299

32 UA: https://orcid.org/0000-0003-4319-9315

33 AdA: https://orcid.org/0000-0001-8513-7804

34 ATP: http://orcid.org/0000-0003-0243-2379

35 JS: https://orcid.org/0000-0003-2160-4148 


\section{ABSTRACT}

37 The Asian giant hornet (AGH, Vespa mandarinia) is the world's largest hornet, occurring

38 naturally in the Indomalayan region, where it is a voracious predator of pollinating insects

39 including honey bees. In September 2019, a nest of Asian giant hornets was detected outside of

40 Vancouver, British Columbia, multiple individuals were detected in British Columbia and

41 Washington state in 2020, and another nest was found and eradicated in Washington state in

42 November 2020, indicating that the AGH could have successfully wintered in North America.

43 Because hornets tend to spread rapidly and become pests, reliable estimates of the potential

44 invasive range of $V$. mandarinia in North America are needed to assess likely human and

45 economic impacts, and to guide future eradication attempts. Here, we assess climatic suitability

46 for AGH in North America, and suggest that, without control, this species could establish

47 populations across the Pacific Northwest and much of eastern North America. Predicted suitable

48 areas for AGH in North America overlap broadly with areas where honey production is highest,

49 as well as with species-rich areas for native bumble bees and stingless bees of the genus

50 Melipona in Mexico, highlighting the economic and environmental necessity of controlling this

51 nascent invasion.

52

53 Keywords: Asian giant hornet, dispersal simulation, ecological niche modeling, invasive

54 species, pollinator threats 
55

56

57

58

59

60

61

62

63

64

65

66

67

68

69

70

71 spring, each queen starts a new colony in a pre-existing cavity, typically in tree roots or an

72 abandoned rodent nest (Archer, 2008). Like other species of Vespa, AGH is a voracious predator

73 of insects, and is notable for preying on bees and other social Hymenoptera. Attacks on honey

74 bee hives occur late in the development of the hornet colony and prior to the emergence of

75 reproductive individuals (males and new queens), the timing of which depends on location (e.g.,

76 Matsuura \& Sakagami, 1973; Matsuura, 1988; Archer, 2008). 
In its native range, AGH attacks several species of bees, some of which have developed

78

79

80

81

82

83

84

sophisticated defense mechanisms against attacks (Ono et al., 1995; Kastberger, Schmelzer \&

Kranner, 2008; Fujiwara, Sasaki \& Washitani, 2016). The best documented, colony-level defense mechanism is in the Asiatic honey bee, Apis cerana Fabricius, which can detect site-marking pheromones released by AGH scouts, and responds by engulfing a single hornet in a ball consisting of up to 500 bees. The heat generated by the vibration of the bees' flight muscles, and the resulting high levels of $\mathrm{CO}_{2}$ from respiration effectively kill the hornet (Ono et al., 1995; Sugahara, Nishimura \& Sakamoto, 2012). In contrast, European honey bees (A. mellifera L.) does not detect and respond to AGH marking pheromones, and colonies are mostly defenseless against AGH attacks (McClenaghan et al., 2019). In Japan, as few as a dozen AGH can destroy a European honey bee colony of up to 30,000 individuals, and extirpate thousands of beehives annually (Matsuura \& Sakagami, 1973).

In addition to the potential threat to the beekeeping industry (Alanis et al. 2020), the introduction of AGH in North America is also concerning for public health. Their powerful stings can induce severe allergic reactions or even death in hypersensitive individuals and sometimes have long-term health efects in people who receive multiple stings (Schmidt et al., 1986; Yanagawa et al., 2007). Annually, as many as 30-40 people may have die from AGH stings in Japan, most as a result of anaphylaxis or sudden cardiac arrest (Matsuura \& Sakagami, 1973); similar deadly cases have been reported from China during outbreak events (Li et al., 2015). Although invasive species are typically limited by dispersal ability and suitability of novel environments, vespid hornets are well known for their invasive success and excellent dispersal capacity (Beggs et al., 2011; Monceau, Bonnard \& Thiéry, 2014). As such, the introduction of AGH in the Pacific Northwest is already presenting a potentially serious ecological and socio- 
100 economic risk in North America. Here, we use ecological niche modeling (ENM) to detect areas

101 of suitable environments for this species worldwide, with particular emphasis on North America.

102 We also use a dispersal simulation approach to detect potential invasion paths of this species

103 within North America. A similar methodology for projecting AGH invasion potential has been

104 implemented by Zhu et al. (2020); we build upon this framework by introducing several

105 modifications to the modelling approach, and investigating further the potential ecological

106 impact on the species richness of the genus Bombus and Melipona as well as the possible

107 economic effects of an AGH invasion in North America.

108 Methods

109

110

111

112

113

114

115

116

117

118

119

120

121

122

\section{Occurrence and environmental data}

We downloaded occurrence data for $V$. mandarinia from the Global Biodiversity Information Facility database (GBIF; https://www.gbif.org/). We kept records from the species' native range (Fig. 1) separate from non-native occurrences facilitated by human introduction. We cleaned occurrences from the native distribution following Cobos et al. (2018) by removing duplicates and records with inconsistent georeferencing (coordinates outside country limits, on the sea, or missing, as recommended in the literature of data cleaning; Chapman, 2005). To avoid model fitting derived from spatial autocorrelation and overdominance of specific regions due to sampling bias, we thinned these records spatially in two ways: by geographic distance and by density of records per country (Fig. 2). In the first case (distance-based thinning; Anderson, 2012), we excluded occurrences that were $<50 \mathrm{~km}$ away from another occurrence record. In the second thinning approach (country-density thinning), we accounted for potential differences in survey and reporting activities among countries and randomly reduced numbers of occurrences in countries with the densest sampling, namely Japan, Taiwan, and South Korea (from 30, 6, and 
1235 , to 6, 2, and 2 occurrences, respectively), to match the approximate reference density of India,

124 Nepal, and China. We used the package ellipsenm (Cobos et al., 2020; available at

125 https://github.com/marlonecobos/ellipsenm) in R 3.6.2 (R Core Team, 2019) to clean and thin

126 the data. We retained 172 occurrence records for $V$. mandarinia after initial data cleaning, 49

127 records after the distance-based thinning approach, and 18 records after the country-density

128 thinning approach (Fig. 1). We then treated both data sets independently in all subsequent 129 analysis steps.

130 For environmental predictors, we used bioclimatic variables at $10^{\prime}$ resolution $(\sim 18 \mathrm{~km}$ at

131 the Equator) from the MERRAclim database (Vega, Pertierra \& Olalla-Tárraga, 2018). We

132 excluded four variables because they are known to contain spatial artifacts as a result of

133 combining temperature and humidity information (Escobar et al., 2014): mean temperature of

134 most humid quarter, mean temperature of least humid quarter, specific humidity mean of

135 warmest quarter, and specific humidity mean of coldest quarter. The 15 variables remaining were 136 masked to an area for model calibration (M, see Ecological niche modeling).

These 15 variables were further processed into two subsets, each used separately in all subsequent analyses. One set consisted of submitting the variables to a principal component analysis (PCA) to reduce dimensionality and multicollinearity. The other set was created with the

140 raw environmental variables that had a Pearson's correlation coefficient $\leq 0.85$ measured in the

141 calibration area, choosing the most biologically relevant or interpretable variables based on our

142 knowledge of AGH natural history (Simões et al., 2020). As a result of this selection process, we

143 obtained six raw variables: isothermality (BIO3), maximum temperature of warmest month

144 (BIO5), minimum temperature of coldest month (BIO6), temperature annual range (BIO7),

145 specific humidity of most humid month (BIO13), and specific humidity of least humid month 
146 (BIO14). The PCA was performed with the raw variables masked to the M area, and principal

147 components for the entire world were obtained by transforming raw variables (at world extent)

148 using the scaling and rotations from the PCA obtained for M. Projecting the PCA results from

149 the accessible area to the entire world ensures that values are comparable and prevents further

150 problems when models are projected. For further analyses, we kept the first four PC axes, as they

151 explained $97.9 \%$ of the cumulative variance (Figure S1). All analyses were done in R;

152 specifically, raster processing was completed using the packages raster (Hijmans et al., 2020),

153 rgeos (Bivand et al., 2020b), and rgdal (Bivand et al., 2020a); PCA was performed using the

154 ntbox package (Osorio-Olvera et al., 2020).

155

\section{Ecological niche modeling}

157 To identify a calibration area (ostensibly equivalent to $\mathbf{M}$; Owens et al., 2013) for our

158 models, we considered a region contained within a buffer of $500 \mathrm{~km}$ around the known

159 occurrence records after the $50 \mathrm{~km}$ thinning process (Fig. 1). This distance was selected

160 considering that little is known about the species' dispersal ability (Matsuura \& Sakagami, 1973;

161 APHIS, 2020a), as no information exists about queens' dispersal capacities; however, we

162 consider that given the species body size, long-distance dispersal events should not be discarded.

163 We used all pixels in $\mathbf{M}(15,411)$ as the background across which to calibrate the models.

Given uncertainty deriving from specific treatments of occurrence records and

environmental predictors in ecological niche modeling (Alkishe et al., 2020), we calibrated

models via four distinct schemes: (1) using raw variables and distance-based thinned 
168 variables and country-density thinned occurrences, and (4) using PCs and country-density

169 thinned occurrences (Fig. 2). For each scheme, we calibrated models five times, each time

170 randomly selecting $50 \%$ of the occurrences for calibrating models (random k-fold evaluation,

171 where $\mathrm{k}=5$ ), and using the remaining records for testing (Cobos et al., 2019a).

Each process of model calibration consisted of creating and evaluating candidate models

173 using Maxent (Phillips, Anderson \& Schapire, 2006; Phillips et al., 2017). Since many choices

174 are needed to parameterize Maxent (Merow, Smith \& Silander, 2013), we chose distinct

175 parameter settings: 10 regularization multiplier values $(0.10,0.25,0.50,0.75,1,2,3,4,5,6)$,

176 eight feature classes (lq, lp, lqp, qp, q, lqpt, lqpth, lqph, where 1 is linear, q is quadratic, $\mathrm{p}$ is

177 product, $\mathrm{t}$ is threshold, and $\mathrm{h}$ is hinge), and all combinations of more than two predictor variables

178 (Cobos et al., 2019b; Table S1-S2). This resulted in a total of 4560 models using raw variables

179 and 880 using PCs that were tested, in tandem with the two subsets of occurrence data described

180 above. We assessed model performance using partial ROC (for statistical significance; Peterson,

181 Papeş \& Soberón, 2008), omission rates ( $E=5 \%$, for predictive ability; Anderson, Lew \&

182 Peterson, 2003), and Akaike Information Criterion corrected for small sample sizes (AICc, for

183 model complexity; Warren \& Seifert, 2011). We selected models with delta AICc $\leq 2$ (Cobos et

184 al., 2019a) from those that were statistically significant and had omission rates below 5\%.

After model calibration, we created models with the selected parameter values, using all occurrences after the corresponding thinning process, with 10 bootstrap replicates, cloglog output (Phillips et al., 2017), and model transfers using three types of extrapolation (free extrapolation, extrapolation with clamping, no extrapolation; Owens et al., 2013). Not all consider those models in further analyses (Fig. 2; Table 1). As a final evaluation step, we 
191 binarized all model replicates given a modified least presence ( $5 \%$ of omission) and then tested 192 whether each replicate of the selected models was able to anticipate the known invasive records 193 of the species in British Columbia, Canada and Washington, USA. For each scheme, using only 194 those model replicates that met the selection criteria and correctly predicted independent 195 196 197 number of coincidences; Pearson et at. 2007; Fig. 2). Our exploration of different modeling pipelines allowed us to highlight how different methodologies produce different results.

As we transferred models to the entire world, we used the mobility-oriented parity metric 202 (MOP; Owens et al., 2013) to detect areas where strict or combinational extrapolation risks could 203 be expected, given the presence of non-analogous conditions with respect to the environments 204 manifested across the calibration area. The areas where extrapolation risks were detected using 205 MOP were deleted from our binary results (suitable areas) to avoid potentially problematic interpretations based on extrapolative situations. Model calibration, production of selected 207 models with replicates, and MOP analyses were done in R using the package kuenm (Cobos et al., 2019a); raster processing and independent testing of models were done using the package 209 raster in $\mathrm{R}$. 
211

212

213

214

215

216

217

218

219

220

221

222

223

224

225

226

227

228

229

230

231

232

233

\section{Dispersal simulations}

We used the binary outputs from the final consensus models (suitable and unsuitable areas, without areas of strict extrapolation) to simulate invasion dynamics of the AGH. All simulations were started from the Pacific Northwest, from sites already known to be occupied by

the AGH. The simulations were performed using the cellular automaton dynamic model included in the bam R package (Osorio-Olvera \& Soberón, 2020; available at https://github.com/luismurao/bam). Under this discrete model, given an occupied area at time $t$, two layers of information are needed to obtain the occupied area at time $t+1$ : (i) the binary layer of suitability for the species, and (ii) a connectivity matrix determined by the species' ability to reach neighboring cells in one time unit (known as "Moore's neighborhood"; Gray et al., 2003, that defines patches that are connected by dispersal). At each step, each of the suitable cells can be either occupied or not by the species. If a cell is occupied, adjacent cells can be visited by the species, and if suitable, they become occupied. This method is similar to the one implemented in the MigClim R package (Engler, Hordijk \& Guisan, 2012), but uses a simpler dispersal kernel and parameterization.

With each of the final consensus models for $V$. mandarinia, we performed a set of simulations in which we explored different degrees of connectivity $(1,2,4,8,10$, and 12 neighbor cells pixels per unit time) and different suitability thresholds (10 equidistant levels from $3-10 \%$ of the presence points to explore variability in sensitivity to the amount of area classified as suitable) to create the binary maps. Since no information is available about dispersal capacities of queens of $V$. mandarinia, all simulations were done with 200 arbitrary time steps that ensure reaching a steady state. In the end, we visualized the simulation results by summing the occupied distribution layers obtained from each set of simulations. A value of 100 in these 
234 final layers means that the species reached that cell in $100 \%$ of the simulations, whereas a value

235 of 0 means that the species never reached that cell. Further details regarding the simulation

236 processes can be found in the Supplementary Information.

238

239

240

241

242

243

244

245

246

247

248

249

250

251

252

253

254

255

256

Honey production and native bee richness in North America

To explore potential ecological and economic impacts of the invasion of the AGH in North America, we explored annual, state-level production of honey (for Mexico, Untied States, and Canada) as well as species richness of bumble bees (Bombus Latreille) and stingless bees of the genus Melipona Illiger in Mexico and the United States. We extracted data on 2016 honey production (in US dollars) for the United States from the U.S. Department of Agriculture (USDA; available at https://quickstats.nass.usda.gov/\#4A0314DA-F3E5-3B06-ADD1CA8032FBD937), from the Instituto Nacional de Estadística, Geografía e Informática (INEGI) for Mexico (https://atlasapi2019.github.io/cap4.html), and from the government of Canada website (https://www.agr.gc.ca/eng/horticulture/horticulture-sector-reports/statistical-overviewof-the-canadian-honey-and-bee-industry-2018/?id=1571143699779) for Canada. For native species richness, we obtained a list of species of bumble bees and stingless bees of the genus Melipona that occur in Mexico and the United States from Discover Life (https://www.discoverlife.org/) and downloaded their occurrence data from GBIF. We chose these bee taxa as likely targets of AGH because the species in these groups are of similar body size and behavior to the typical prey of these hornets: they are social insects that form annual or perennial colonies that can have a few hundreds to as many as 10,000 individuals (Cueva del Castillo, Sanabria-Urbán \& Serrano-Meneses, 2015; Viana et al., 2015), and store honey and pollen inside their nests (Michener, 2000). To summarize species richness of these two genera, 
257 we created a presence absence matrix (PAM; Arita et al., 2008) for North America, based on

258 geographic coordinates of occurrence data, with a pixel size of one degree. The PAM was

259 created in R with the package biosurvey (Nuñez-Penichet et al., 2020; available at

260 https://github.com/claununez/biosurvey).

261

To assure transparency and reproducibility of our work, we include an Overview, Data,

262 Model, Assessment, and Prediction protocol (ODMAP; Zurell et al., 2020) in our supplementary

263 materials. This metadata summary provides a detailed key to the steps of our analyses. The data

264 and $\mathrm{R}$ code used in this research are openly available at http://hdl.handle.net/1808/30602 and

265 https://github.com/townpeterson/vespa repositories, respectively.

266

\section{Results}

268

269

270

271

272

273

274

275

276

277

\section{Model calibration}

The number of models that met the selection criteria was considerably smaller than the total number of models tested (Table 1, see Supplemental information for more details of the calibration results). The calibration schemes including raw variables had fewer models selected than those using PCs $(11,19,6,15$ models selected for raw/distance-thinned, PC/distancethinned, raw/country-density, and PC/country-density, respectively). Not all replicates of selected models anticipated the $V$. mandarinia invaded areas in North America successfully, so we kept only those that predicted all known invasive records. The number of replicates retained varied among distinct calibration schemes and types of extrapolation used (Table 1). 


\section{Ecological niche model predictions}

279 In our models, areas predicted as suitable for the AGH varied among calibration schemes,

280 in both extension and geographic pattern (Fig. 3, Figures S2-S4). The differences are

281 conspicuous between the two types of thinning approaches, which resulted in models created

282 with different numbers of occurrence records. Models with country-density thinning (18 records)

283 resulted in broad predicted suitable areas worldwide, with areas of higher values of suitability

284 concentrated in tropical regions (Fig. 3, Figures S2-S4). In contrast, models created with the

285 greater number of occurrences (49 records) from the geographic distance thinning predicted

286 more patches of suitable areas across large extensions of Southeast Asia, Europe, West Africa,

287 Central America, northern South America, and the Pacific Northwest and southeastern United

288 States (Fig. 3, Figures S2-S4). In the calibration area, the areas detected with high levels of

289 suitability were larger in the scheme with geographic distance thinned occurrences and the raw

290 variables and smaller in the predictions obtained with the country-density thinned occurrences

291 and the PCs as environmental predictors (Fig. 3). In all schemes, the two northernmost

292 occurrence points of this species in China were accorded relatively low levels of suitability (Fig.

293 3). Predicted suitable areas for this hornet worldwide were also different among types of

294 extrapolation considered in this study, especially as regards its distribution size rather than

295 location (Figures S2-S4).

In North America, across multiple model calibration schemes, our various models agreed

297 in predicting suitable areas for AGH in the Pacific region of southwestern Canada, the Pacific

298 Northwest, the southeastern United States, and from central Mexico south to southernmost

299 Panama (Fig. 4). Our model calibration schemes also agreed in identifying the Rocky Mountains

300 and Great Plains as unsuitable for this species (Fig. 4). 
302 the case of models created with raw variables, the proportion was 0.171 and 0.164 for spatially

303 thinned and country-density thinned records, respectively. When PCs were used, suitable

304 proportions were 0.248 and 0.239 , for spatially thinned and country-density thinned records, 305 respectively (Table S3).

306

307

308

309

310

311

312

313

314

315

316

317

318

319

320

321

322

\section{Extrapolation risks in model projections}

The pattern of areas detected with risk of extrapolation was similar worldwide between thinning methods, but different between raw variables and PCs (Fig. 5, Figure S8). Most tropical areas predicted as suitable were identified as regions with high extrapolation risk (Figure S8). For raw variables, the areas with extrapolation risk in North America included most of Canada and Alaska, whereas for PCs areas with extrapolation risk included large portions of Mexico and, the central-southwestern United States, as well as the islands north of Hudson Bay in Canada (Fig. 5).

\section{Simulations of potential invasion}

The simulations of potential sequences of colonization and dispersal of AGH in North America, starting from the known invaded localities, showed agreement among calibration schemes in predicting an invasion across the Pacific Northwest from southernmost Alaska to southernmost California in the United States (Fig. 6). In contrast, we found that the dispersal distance required to invade all the way to the East Coast of North America varied among calibration schemes. In the schemes using raw variables, the route of invasion to reach the East Coast goes from the Pacific Northwest down to California and Mexico, and then up the East 
323 Coast of North America. A dispersal distance of 10 cells (where each cell represents $\sim 18 \mathrm{~km}$ )

324 was enough to reach the East Coast (see A and C panels in Fig. 6). For the scheme using the 50

$325 \mathrm{~km}$ spatially-thinned occurrences and PCs, the invasion follows a more direct route from the

326 Pacific Northwest to the East Coast that goes through the United States, and the required

327 dispersal distance to reach the East Coast was only 4 cells (Fig. 6B). Finally, in the case of

328 country-density thinned occurrences and PCs, the invasion goes from the Pacific Northwest

329 through Canada to the Atlantic, and then down the East Coast to the United States. A distance of

3308 cells was needed to make this invasion route possible (Fig. 6D).

331

332

333

334

335

336

337

338

339

340

341 processing schemes are broadly concurrent with the results obtained by Zhu et al. (2020) and

342 Alaniz et al. (2020) (Fig. 6), who used an ensemble modeling approach for the potential invasion 343

\section{Honey production and native bee richness}

The areas in North America that our models identified as highly suitable for AGH overlapped broadly with the states where honey production is highest. This overlap was particularly noticeable in southern Mexico and in some states of the Pacific Northwest and eastern US (Fig. 7). We found a similar pattern with the species richness of Bombus and Melipona.

Discussion

The patterns of suitability that we found in North America across multiple input data of AGH. This concordance with the results of these works (both among our selected models, and 
344 between our models and the ensemble models), gives us confidence that the Pacific Northwest

345 and southeastern United States represent suitable areas for AGH. In contrast with the results of

346 Zhu et al. (2020), however, our dispersal simulations indicate a larger potential invasion area in

347 the United States, with the AGH potentially crossing to eastern North America via a southern

348 invasion route, through Mexico and Texas; a southeast-ward route crossing Idaho, Wyoming,

349 and Colorado; or a northern route across Canada and the Great Lakes region (Fig. 6).

Quantifying the probability of the AGH following any one of the individual dispersal

351

352

353

354

355

356

357

358

359

360

361

362

363

364

365

366

routes presented would require precise quantification of dispersal ability, and discerning the real-

world validity of each of the four modeling outcomes. Instead of attempting to guess, we present several models that offer multiple plausible invasion scenarios. Across all scenarios presented, the AGH is expected to establish populations along the coastal Pacific Northwest via shortdistance dispersal, and it is likely to invade the southeastern United States if it has even moderate dispersal potential (Fig. 6). It is important to note that these potential invasion routes consider only the natural dispersal ability of this hornet, and do not take into account the effect of potential accidental human-aided dispersal through the transport of soil and wood, where fertilized queen AGHs overwinter (Archer, 1995). Such unwitting human-aided dispersal is a serious concern, as it could potentiate a rapid invasion of this hornet to environmentally suitable, yet currently isolated places across North America. Our simulations allowing AGH to disperse to larger numbers of neighbor cells are perhaps a good illustration of what could be expected if dispersal events to very long distances occur. more conservative predictions, arise from Zhu et al.'s (2020) use of MigClim (Engler, Hordijk \& Guisan, 2012) to model dispersal of the AGH in western North America. MigClim is a cellular 
367 automaton platform that models the state of grid cells as occupied or unoccupied. Although we

368 used the same modelling technique, our dispersal kernel is a much simpler "Moore

369 Neighborhood" (Gray et al., 2003) approach, in which cells surrounding an occupied focal cell

370 (to $1,2 \ldots d$ neighbors) may become occupied, depending on their suitability. MigClim instead

371 assumes a probabilistic contagion model that requires parameter estimates for number of

372 propagules, and short- and long-distance-decay rates. Given the lack of empirical data to inform

373 values for those parameters, we prefer a simpler algorithm to explore how connected clusters of

374 suitable cells are across different values of the single parameter $d$. Another factor resulting in

375 these differences is the number of simulation steps used in our approach (200). From a biological

376 perspective, this implies that 200 dispersal events resulting in colonization of suitable cells

377 happened. Although this number may appear excessive, it gives a view of a scenario in which no 378 action is taken to prevent AGH invasion in North America and the species builds to large local

379 populations. For a more conservative view of the expected invasion, one could concentrate in 380 areas with high values of suitability on the layers obtained from our simulations.

The areas in North America that our models identified as highly suitable for this hornet

382 overlap broadly with the states where honey production is highest, and species richness of

383 Bombus and Melipona are highest (Fig. 7). These results give credence to public concerns that, if 384 established, the AGH could pose a serious economic threat to the beekeeping industry in Oregon, 385 northern California, Georgia, Alabama, and Florida. In the United States alone, the European 386 honey bee provides at least $\$ 15$ billion worth of pollination services and generates between $\$ 300$ 387 and 500 million in harvestable honey and other products each year (Calderone, 2012). Indeed, 388 Alaniz et al. (2020) estimate that if spread across the US, the AGH could threaten between 11 389 and 100 million dollars for hive derived products and honey bee-pollinated crops production. In 
390 Mexico, impacts on the honey bee industry are also expected in tropical areas of the country that

391 have suitable areas for the AGH, particularly in the states of Yucatán, Campeche, and Quintana

392 Roo. Beekeepers in the United States and Mexico may have to adopt mitigation practices to

393 avoid serious losses, such as those developed by Japanese beekeepers including the use of

394 protective screens or traps at the hive entrance that can exclude AGHs based on body size

395 (Matsuura \& Sakagami, 1973; Mahdi, Glaiim \& Ibrahim, 2008). Potential establishment of the

396 AGH in North America adds an additional layer of environmental and economic stress to a

397 beekeeping industry already suffering from high annual hive mortality rates resulting from the

398 combined effects of pesticides, diseases, and poor nutrition (Goulson et al., 2015).

The ecological impact of AGH on the local bee fauna is more challenging to predict than

the economic impact on honey production, because it is not clear which native bee species would

401 be particularly targeted by AGH in North America. We explore Bombus and Melipona species as potential prey candidates of AGH because, among the $>4000$ bee species occurring in this region

403 (Ascher \& Pickering, 2020), these two groups of bees are social, locally abundant, and make

404 annual or perennial colonies (Michener, 2007; Cueva del Castillo, Sanabria-Urbán \&

405 Serrano-Meneses, 2015; Viana et al., 2015). Thus, they may represent predictable food sources

406 for the AGH, particularly in areas where bee colonies remain active year-round. It is crucial to

407 consider this potential threat because both Bombus and Melipona bees are important pollinators

408 that have already experienced population losses and local extirpations, reflecting changes in

409 landscape and agricultural intensification (Brown \& Albrecht, 2001; Cameron et al., 2011).

410 Furthermore, these North American bee species are predicted to lack the specialized behavioral 411 responses exhibited by the Asian honey bee, which makes them vulnerable to the attacks of the

412 AGH. The economic and cultural importance of Melipona species in America is well- 
413 documented, particularly in the Yucatan Peninsula in Mexico, where these bees have been

414 traditionally raised for honey and were even considered gods outright in Mayan times (Ayala,

415 Gonzalez \& Engel, 2013; Quezada-Euán et al., 2018). It is important to mention, however, that

416 the risk to Melipona species may be lower than that to Bombus species because entrances to the

417 hives of some species of Melipona are narrow, allowing a single bee to pass at a time (Couvillon

418 et al., 2007), unlike the entrances to the hives of honey bees and many bumble bees, which are

419 wider.

420

The AGH is not the first Hymenoptera to invade North America, and species of Vespa are

421 well-known for their invasive success and excellent dispersal capacity (Beggs et al., 2011;

422 Monceau, Bonnard \& Thiéry, 2014). The European hornet, Vespa crabro L., a Eurasian species

423 that was accidentally introduced to North America in the 1800s, occupies a range in the United

424 States that encompasses most state east of the Great Plains (Smith-Pardo et al. 2020). The

425 solitary giant resin bee, Challomegachile sculpturalis is an Asian taxon which was recently

426 introduced in the United States. Only 15 years after its initial detection near Baltimore,

427 Maryland, this species had invaded most of the southeastern United States (Hinojosa-Díaz et al.,

428 2005). These examples indicate considerable precedent for hornet invasion and establishment in

429 the southeastern United States, but the AGH poses a unique biodiversity risk as a direct predator

430 of bees. Because the Pacific Northwest is consistently predicted as suitable for the AGH,

431 preventing further establishment and spread of recently detected introduced populations near

432 Seattle and Vancouver is essential. If these introduced individuals are not eradicated, they may

433 flourish under the suitable climatic conditions, establishing many more colonies that will be

434 difficult to control. Preventing establishment of the AGH in the Pacific Northwest is especially

435 critical because an established AGH population in the Pacific Northwest would provide a source 
436 population for potential long-range dispersers that could use multiple potential invasion routes 437 (Fig. 6) to reach suitable habitat in the eastern United States, facilitating full-scale invasion. In 438 light of this, we recommend official monitoring protocols for the vulnerable Pacific Northwest 439 region including on-going citizen science and outreach efforts (https://agr.wa.gov/hornets), 440 which may be the fastest and most effective way to detect potential range expansions. Although AGH is primarily found in temperate areas in its native range, some of its 442 populations reach subtropical regions like Taiwan (Archer, 2008), which indicates a broad 443 temperature tolerance. This southern part of the species' native range might explain why our 444 models predicted suitable areas in South America, Africa, and elsewhere (Figure 2S-S7). 445 Although temperature is a critical factor that determines the abundance and distribution of 446 organisms (Sunday, Bates \& Dulvy, 2012), factors such as desiccation resistance may be equally

447 important for some species. For example, for ants and some bees, desiccation tolerance is a good 448 predictor of species’ distributions (Bujan, Yanoviak \& Kaspari, 2016; Burdine \& McCluney, 449 2019). For example, humidity is important for the regulation of temperature in nests of the 450 European hornet (Klingner et al., 2005) and, in some species of stingless bees, regulation of 451 humidity appears to be more important than regulation of temperature to maintain colony health 452 (Ayton et al., 2016). Unfortunately, heat and desiccation tolerances, factors that might improve 453 predictions of this species' distributional potential, are unknown for the AGH. In other hornets, 454 subtropical populations tend to have longer population cycles than temperate populations 455 (Archer, 2008), so negative impacts of an AGH invasion may be stronger in tropical or 456 subtropical areas. In summary, our modeling approach allowed us to recognize how predicted suitable areas can be depending on distinct schemes of data treatment. We showed that this variability 
459 can derive from crucial decisions made during the initial steps of ecological niche modeling

460 exercises. These results highlight the importance of such initial decisions, as well as the need to

461 recognize sources of variability in predictions of suitability. This point is of special importance

462 in predicting the potential for expansion of invasive species, as uncertainty increases when

463 models are transferred to areas where environmental conditions are different. Our analyses and

464 simulations revealed the potential of the AGH to invade large areas in North America and the

465 likely paths of such an invasion. We also showed that predicted suitable areas for the AGH

466 overlap broadly with those where honey production is highest in the United States and Mexico,

467 as well as with species-rich areas for bumble bees and stingless bees. These results bring light to

468 the potential implications of uncontrolled dispersal of the AGH to suitable environments in

469 North America, and highlight the need for rapid eradication actions to mitigate potential

470 biodiversity and economic losses.

471

472 Acknowledgments

473 We would like to thank the members of the KUENM group for their support in the development

474 of this manuscript. We also thank Allan Smith-Pardo for letting us use the photograph of AGH in

475 lateral view (Fig. 1B). ANB would like to thank Secretaría de Educación, Ciencia, Tecnología e

476 Innovación de la Ciudad de México.

477

\section{References}

479 APHIS. 2020a. New pest response guidelines: Vespa mandarinia. U.S. Department of 
481

482

483

484

485

486

487

488

489

490

491

492

493

494

495

496

497

498

499

500

501

502

503

Quarantine.

APHIS. 2020b. Asian Giant Hornet. U.S. Department of Agriculture, National Invasive Species Information Center. https://www.invasivespeciesinfo.gov/terrestrial/invertebrates/asiangiant-hornet.

Alaniz AJ, Carvajal MA, Vergara PM, 2020. Giants are coming? Predicting the potential spread and impacts of the giant Asian hornet (Vespa mandarinia, Hymenoptera: Vespidae) in the United States. Pest Management Science. DOI: 10.1002/ps.6063.

Alkishe A, Cobos ME, Peterson AT, Samy AM. 2020. Recognizing sources of uncertainty in disease vector ecological niche models: an example with the tick Rhipicephalus sanguineus sensu lato. Perspectives in Ecology and Conservation. DOI: 10.1016/j.pecon.2020.03.002.

Anderson RP. 2012. Harnessing the world's biodiversity data: promise and peril in ecological niche modeling of species distributions. Annals of the New York Academy of Sciences 1260:66-80. DOI: 10.1111/j.1749-6632.2011.06440.x.

Anderson RP, Lew D, Peterson AT. 2003. Evaluating predictive models of species' distributions: criteria for selecting optimal models. Ecological Modelling 162:211-232. DOI: 10.1016/S0304-3800(02)00349-6.

Archer ME. 1995. Taxonomy, distribution and nesting biology of the Vespa mandarinia group (Hym., Vespinae). Entomologist's Monthly Magazine 131:47-53.

Archer ME. 2008. Taxonomy, distribution and nesting biology of species of the genera Provespa Ashmead and Vespa Linneaus (Hymenoptera, Vespidae). Entomologist's Monthly Magazine 144:69-101.

Arita HT, Christen JA, Rodríguez P, Soberón J. 2008. Species diversity and distribution in 
504 505 506 507 508 509 510

presence-absence matrices: mathematical relationships and biological implications. American Naturalist 172:519-532. DOI: 10.1086/590954.

Ascher JS, Pickering J. 2020.Discover life bee species guide and world checklist (Hymenoptera: Apoidea: Anthophila). Available at https://www.discoverlife.org/mp/20q?guide=Apoidea_species (accessed July 1, 2020).

Ayala R, Gonzalez VH, Engel MS. 2013. Mexican stingless bees (Hymenoptera: Apidae): diversity, distribution, and indigenous knowledge. In: Vit P, Pedro SRM, Roubik D eds. Pot-Honey: A Legacy of Stingless Bees. New York, NY: Springer, 135-152. DOI: 10.1007/978-1-4614-4960-7_9.

Ayton S, Tomlinson S, Phillips RD, Dixon KW, Withers PC. 2016. Phenophysiological variation of a bee that regulates hive humidity, but not hive temperature. Journal of Experimental Biology 219:1552-1562. DOI: 10.1242/jeb.137588.

Barve N, Barve V, Jiménez-Valverde A, Lira-Noriega A, Maher SP, Peterson AT, Soberón J, Villalobos F. 2011. The crucial role of the accessible area in ecological niche modeling and species distribution modeling. Ecological Modelling 222:1810-1819. DOI: 10.1016/j.ecolmodel.2011.02.011.

Beggs JR, Brockerhoff EG, Corley JC, Kenis M, Masciocchi M, Muller F, Rome Q, Villemant C. 2011. Ecological effects and management of invasive alien Vespidae. BioControl 56:505-526. DOI: 10.1007/s10526-011-9389-z.

Bérubé C. 2020. Giant alien insect invasion averted Canadian beekeepers thwart apicultural disaster (... or at least the zorn-bee apocalypse). American Bee Journal:209-214.

Bivand R, Keitt T, Rowlingson B, Pebesma E, Sumner M, Hijmans R, Rouault E, Warmerdam F, Ooms J, Rundel C. 2020a. rgdal: Bindings for the "geospatial” data abstraction library. 
527

528

529

530

531

532

533

534

535

536

537

538

539

540

541

542

543

544

545

546

547

548

549

https://cran.r-project.org/web/packages/rgdal/index.html.

Bivand R, Rundel C, Pebesma E, Stuetz R, Hufthammer KO, Giraudoux P, Davis M, Santilli S. 2020b. rgeos: Interface to geometry engine - open source ('GEOS'). https://cran.rproject.org/web/packages/rgeos/index.html.

Brown JC, Albrecht C. 2001. The effect of tropical deforestation on stingless bees of the genus Melipona (Insecta: Hymenoptera: Apidae: Meliponini) in central Rondonia, Brazil. Journal of Biogeography 28:623-634. DOI: 10.1046/j.1365-2699.2001.00583.x.

Bujan J, Yanoviak SP, Kaspari M. 2016. Desiccation resistance in tropical insects: causes and mechanisms underlying variability in a Panama ant community. Ecology and Evolution 6:6282-6291. DOI: 10.1002/ece3.2355.

Burdine JD, McCluney KE. 2019. Differential sensitivity of bees to urbanization-driven changes in body temperature and water content. Scientific Reports 9:1643. DOI: 10.1038/s41598018-38338-0.

Cameron SA, Lozier JD, Strange JP, Koch JB, Cordes N, Solter LF, Griswold TL. 2011. Patterns of widespread decline in North American bumble bees. Proceedings of the National Academy of Sciences USA 108:662-667. DOI: 10.1073/pnas.1014743108.

Chapman AD. 2005. Principles and methods of data cleaning. Copenhagen, GBIF.

Cobos ME, Jiménez L, Nuñez-Penichet C, Romero-Alvarez D, Simões M. 2018. Sample data and training modules for cleaning biodiversity information. Biodiversity Informatics 13:49-50. DOI: 10.17161/bi.v13i0.7600.

Cobos ME, Osorio-Olvera L, Soberón J, Peterson AT, Barve V, Barve N. 2020. ellipsenm: Ecological niche characterizations using ellipsoids. https://github.com/marlonecobos/ellipsenm. 
550 Cobos ME, Peterson AT, Barve N, Osorio-Olvera L. 2019a. kuenm: an R package for detailed 551 development of ecological niche models using Maxent. PeerJ 7:e6281. DOI:

$552 \quad 10.7717 /$ peerj.6281.

553 Cobos ME, Peterson AT, Osorio-Olvera L, Jiménez-García D. 2019b. An exhaustive analysis of 554 heuristic methods for variable selection in ecological niche modeling and species 555 distribution modeling. Ecological Informatics 53:100983. DOI:

556 10.1016/j.ecoinf.2019.100983.

557

558

559

560

561

562

563

564

565

566

567

568

569

570

571

572

Colautti RI, Bailey SA, Van Overdijk CD, Amundsen K, MacIsaac H J. 2006. Characterized and projected costs of nonindigenous species in Canada. Biological invasions 8(1):45-59.

Couvillon MJ, Wenseleers T, Imperatriz-Fonseca VL, Nogueira-Neto P, Ratnieks FLW. 2007. Comparative study in stingless bees (Meliponini) demonstrates that nest entrance size predicts traffic and defensivity. Journal of Evolutionary Biology 21:194-201. DOI: 10.1111/j.1420-9101.2007.01457.x.

Cueva del Castillo R, Sanabria-Urbán S, Serrano-Meneses MA. 2015. Trade-offs in the evolution of bumblebee colony and body size: a comparative analysis. Ecology and Evolution 5:3914-3926. DOI: 10.1002/ece3.1659.

Dueñas M-A, Ruffhead HJ, Wakefield NH, Roberts PD, Hemming DJ, Diaz-Soltero H. 2018. The role played by invasive species in interactions with endangered and threatened species in the United States: a systematic review. Biodiversity and Conservation 27:3171-3183. DOI: 10.1007/s10531-018-1595-x.

Engler R, Hordijk W, Guisan A. 2012. The MIGCLIM R package - seamless integration of dispersal constraints into projections of species distribution models. Ecography 35:872878. DOI: 10.1111/j.1600-0587.2012.07608.x. 
573 Escobar LE, Lira-Noriega A, Medina-Vogel G, Peterson AT. 2014. Potential for spread of the $574 \quad$ white-nose fungus (Pseudogymnoascus destructans) in the Americas: use of Maxent and 575 NicheA to assure strict model transference. Geospatial Health 9:221-229. DOI: 576 10.4081/gh.2014.19.

577 Fujiwara A, Sasaki M, Washitani I. 2016. A scientific note on hive entrance smearing in

578

579

580

581

582

583

584

585

586

587

588

589

590

591

592

593

594

595
Japanese Apis cerana induced by pre-mass attack scouting by the Asian giant hornet Vespa mandarinia. Apidologie 47:789-791. DOI: 10.1007/s13592-016-0432-z.

GBIF.org (07 May 2020) GBIF occurrence download. https://doi.org/10.15468/dl.kzcgc2.

Gray L, New A, Science K, Wolfram S. 2003. A mathematician looks at Wolfram's new kind of science. Notices of the American Mathematical Society 50 (2) (2003) 200-211, URL http://www.ams.org/notices/200302/fea-gray.pdf. URL http://www.ams.org/notices/200302/fea-gray.pdf 50:200-211.

Hijmans RJ, Etten J van, Sumner M, Cheng J, Bevan A, Bivand R, Busetto L, Canty M, Forrest D, Ghosh A, Golicher D, Gray J, Greenberg JA, Hiemstra P, Hingee K, Geosciences I for MA, Karney C, Mattiuzzi M, Mosher S, Nowosad J, Pebesma E, Lamigueiro OP, Racine EB, Rowlingson B, Shortridge A, Venables B, Wueest R. 2020. raster: Geographic data analysis and modeling. https://cran.r-project.org/web/packages/raster/index.html.

Hinojosa-Díaz IA, Yáñez-Ordóñez O, Chen G, Peterson AT, Engel MS. 2005. The North American invasion of the giant resin bee (Hymenoptera: Megachilidae). Journal of Hymenoptera Research 14:69-77.

Kastberger G, Schmelzer E, Kranner I. 2008. Social waves in Giant Honeybees repel hornets. PLOS ONE 3:e3141. DOI: 10.1371/journal.pone.0003141.

Klingner R, Richter K, Schmolz E, Keller B. 2005. The role of moisture in the nest 
thermoregulation of social wasps. Naturwissenschaften 92:427-430. DOI:

597 10.1007/s00114-005-0012-y.

598

599

600

601

602

603

604

605

606

607

608

609

610

611

612

613

614

615

616

617

618

Li X-D, Liu Z, Zhai Y, Zhao M, Shen H-Y, Li Y, Zhang B, Liu T. 2015. Acute interstitial nephritis following multiple Asian Giant Hornet stings. American Journal of Case Reports 16:371-373. DOI: 10.12659/AJCR.893734.

Matsuura M. 1988. Ecological study on Vespine wasps (Hymenoptera: Vespidae) attacking honeybee colonies: 1. Seasonal changes in the frequency of visits to apiaries by Vespine wasps and damage inflicted, especially in the absence of artificial protection. Applied Entomology and Zoology 23:428-440.

Matsuura M, Sakagami SF. 1973. A bionomic sketch of the Giant Hornet, Vespa mandarinia, a serious pest for Japanese apiculture. Journal of the Faculty of Science, Hokkaido University: Series 6. Zoology 19:125-162.

McClenaghan B, Schlaf M, Geddes M, Mazza J, Pitman G, McCallum K, Rawluk S, Hand K, Otis GW. 2019. Behavioral responses of honey bees, Apis cerana and Apis mellifera, to Vespa mandarinia marking and alarm pheromones. Journal of Apicultural Research 58:141-148. DOI: 10.1080/00218839.2018.1494917.

Merow C, Smith MJ, Silander JA. 2013. A practical guide to MaxEnt for modeling species’ distributions: what it does, and why inputs and settings matter. Ecography 36:1058-1069. DOI: $10.1111 /$ j.1600-0587.2013.07872.x.

Michener CD. 2000. The Bees of the World. Baltimore: Johns Hopkins University Press. Michener CD. 2007. The Bees of the World. Baltimore: Johns Hopkins University Press. Monceau K, Bonnard O, Thiéry D. 2014. Vespa velutina: a new invasive predator of honeybees in Europe. Journal of Pest Science 87:1-16. DOI: 10.1007/s10340-013-0537-3. 
619 Nuñez-Penichet C, Cobos ME, Peterson AT, Soberón J, Barve N, Barve V, Gueta T. 2020.

620

biosurvey: Tools for biological survey planning. https://github.com/claununez/biosurvey.

621 Ono M, Igarashi T, Ohno E, Sasaki M. 1995. Unusual thermal defense by a honeybee against 622 mass attack by hornets. Nature 377:334-336. DOI: 10.1038/377334a0.

623 Osorio-Olvera L, Soberón J. 2020. bam: Species distribution models in the light of the BAM 624 theory. https://github.com/luismurao/bam.

625 Osorio-Olvera L, Lira-Noriega A, Soberón J, Peterson AT, Falconi M, Contreras-Díaz RG, 626 Martínez-Meyer E, Barve N, Barve V. 2020. NTBOX: an R package with a graphical

627 user interface for modeling and evaluating multidimensional ecological niches. Methods

628 in Ecology and Evolution 11(10): 1199-11206. DOI: 10.1111/2041-210X.13452.

629

630

631

632

633

634

635

636

637

638

639

640

641

Owens HL, Campbell LP, Dornak LL, Saupe EE, Barve N, Soberón J, Ingenloff K, Lira-Noriega A, Hensz CM, Myers CE, Peterson AT. 2013. Constraints on interpretation of ecological niche models by limited environmental ranges on calibration areas. Ecological Modelling 263:10-18. DOI: 10.1016/j.ecolmodel.2013.04.011.

Pearson RG, Raxworthy CJ, Nakamura M, Peterson AT. 2007. Predicting species distributions from small numbers of occurrence records: a test case using cryptic geckos in Madagascar. Journal of Biogeography 34(1):102-117.

Peterson AT, Papeş M, Soberón J. 2008. Rethinking receiver operating characteristic analysis applications in ecological niche modeling. Ecological Modelling 213:63-72. DOI: 10.1016/j.ecolmodel.2007.11.008.

Phillips SJ, Anderson RP, Dudík M, Schapire RE, Blair ME. 2017. Opening the black box: an open-source release of Maxent. Ecography 40:887-893. DOI: 10.1111/ecog.03049.

Phillips SJ, Anderson RP, Schapire RE. 2006. Maximum entropy modeling of species 
642

643

644 Pimentel D, Zuniga R, Morrison D. 2005. Update on the environmental and economic costs

645

646

647

648

649

650

651

652

653

654

655

656

657

658

659

660

661

662

663

664

geographic distributions. Ecological Modelling 190:231-259. DOI:

10.1016/j.ecolmodel.2005.03.026.

associated with alien-invasive species in the United States. Ecological Economics

52:273-288. DOI: 10.1016/j.ecolecon.2004.10.002.

Pyšek P, Richardson DM. 2010. Invasive species, environmental change and management, and health. Annual Review of Environment and Resources 35:25-55. DOI: 10.1146/annurevenviron-033009-095548.

Quezada-Euán JJG, Nates-Parra G, Maués MM, Roubik DW, Imperatriz-Fonseca VL. 2018. The economic and cultural values of stingless bees (Hymenoptera: Meliponini) among ethnic groups of tropical America. Sociobiology 65:534-557. DOI:

10.13102/sociobiology.v65i4.3447.

R Core Team. 2019. R: A language and environment for statistical computing. Vienna, Austria: R Foundation for Statistical Computing.

Schmidt JO, Yamane S, Matsuura M, Starr CK. 1986. Hornet venoms: lethalities and lethal capacities. Toxicon 24:950-954. DOI: 10.1016/0041-0101(86)90096-6.

Simões M, Romero-Alvarez D, Nuñez-Penichet C, Jiménez L, Cobos ME. 2020. General theory and good practices in ecological niche modeling: a basic guide. Biodiversity Informatics $15: 67-68$.

Smith-Pardo AH, Carpenter JM, Kimsey L. 2020. The diversity of hornets in the genus Vespa (Hymenoptera: Vespidae; Vespinae), their importance and interceptions in the United States. Insect Systematics and Diversity 4:1-27.

Sugahara M, Nishimura Y, Sakamoto F. 2012. Differences in heat sensitivity between Japanese 
honeybees and hornets under high carbon dioxide and humidity conditions inside bee balls. Zoological Science 29:30-36. DOI: 10.2108/zsj.29.30.

667 Sunday JM, Bates AE, Dulvy NK. 2012. Thermal tolerance and the global redistribution of 668 animals. Nature Climate Change 2:686-690. DOI: 10.1038/nclimate1539.

669

670

671

672

673

674

675

676

677

678

679

680

681

682

683

684 685

686

687

Vega GC, Pertierra LR, Olalla-Tárraga MÁ. 2018. MERRAclim, a high-resolution global dataset of remotely sensed bioclimatic variables for ecological modelling. Scientific Data 4:170078. DOI: $10.1038 /$ sdata.2017.78.

Viana JL, Sousa H de AC, Alves RM de O, Pereira DG, Silva Jr. JC, Paixão JF da, Waldschmidt AM, Viana JL, Sousa H de AC, Alves RM de O, Pereira DG, Silva Jr. JC, Paixão JF da, Waldschmidt AM. 2015. Bionomics of Melipona mondury Smith 1863 (Hymenoptera: Apidae, Meliponini) in relation to its nesting behavior. Biota Neotropica 15. DOI: $10.1590 / 1676-06032015009714$.

Vilà M, Espinar JL, Hejda M, Hulme PE, Jarošík V, Maron JL, Pergl J, Schaffner U, Sun Y, Pyšek P. 2011. Ecological impacts of invasive alien plants: a meta-analysis of their effects on species, communities and ecosystems. Ecology Letters 14:702-708. DOI: 10.1111/j.1461-0248.2011.01628.x.

Warren DL, Seifert SN. 2011. Ecological niche modeling in Maxent: the importance of model complexity and the performance of model selection criteria. Ecological Applications 21:335-342. DOI: 10.1890/10-1171.1.

Wilcove DS, Rothstein D, Dubow J, Phillips A, Losos E. 1998. Quantifying threats to imperiled species in the United States. BioScience 48:607-615. DOI: 10.2307/1313420.

Wilson TM, Takahashi J, Spichiger S-E, Kim I, van Westendorp P. 2020. First reports of Vespa mandarinia (Hymenoptera: Vespidae) in North America represent two separate maternal 
688 lineages in Washington State, United States, and British Columbia, Canada. Annals of the 689 Entomological Society of America 113:468-472. DOI: 10.1093/aesa/saaa024.

690 Yanagawa Y, Morita K, Sugiura T, Okada Y. 2007. Cutaneous hemorrhage or necrosis findings

691 after Vespa mandarinia (wasp) stings may predict the occurrence of multiple organ

692 injury: a case report and review of literature. Clinical Toxicology 45:803-807. DOI:

$693 \quad 10.1080 / 15563650701664871$.

694 Zhu G, Illan JG, Looney C, Crowder DW. 2020. Assessing the ecological niche and invasion

695 potential of the Asian giant hornet. Proceedings of the National Academy of Sciences

$696 \quad U S A$. DOI: 10.1073/pnas.2011441117.

697 Zurell D, Franklin J, König C, Bouchet PJ, Dormann CF, Elith J, Fandos G, Feng X,

698 Guillera-Arroita G, Guisan A, Lahoz-Monfort JJ, Leitão PJ, Park DS, Peterson AT,

699 Rapacciuolo G, Schmatz DR, Schröder B, Serra-Diaz JM, Thuiller W, Yates KL,

700 Zimmermann NE, Merow C. 2020. A standard protocol for reporting species distribution

$701 \quad$ models. Ecography. DOI: 10.1111/ecog.04960. 


\section{Tables}

703 Table 1. Summary of results of ecological niche modeling for Vespa mandarinia, including 704 model calibration, model evaluation, and relevant Maxent settings for models selected after 705 independent testing. Maxent settings are represented in the columns 'Regularization multiplier,'

706 'Feature classes,' and 'Variable sets'. The column 'Calibration processes' refers to each of the 707 five calibrations processes that were done with different sets of random points, for every 708 calibration scheme. The variables included in the sets mentioned on this table can be found in 709 Table 1S-2S. E: free extrapolation; EC: extrapolation with clamping; NE: no extrapolation, PCs: 710 principal components. 


\section{Figures}

712 Figure 1. Hypothesis of accessible areas $(\mathbf{M})$ and representation of the occurrence records of

713 Vespa mandarinia across its native distribution. The three panels represent the occurrences left

714 after cleaning (A) and after applying the two thinning approaches (B and C).

715 Figure 2. Schematic representation of methods used to obtain ecological niche models for Vespa

716 mandarinia. The aim of the modeling process was to consider the variability resulting from

717 different procedures and methodological decisions made during model calibration.

718 Figure 3. Median of potentially suitable areas for Vespa mandarinia predicted with free

719 extrapolation for different calibration schemes in the calibration area (A, C, E, G) and in North

720 America (B, D, F, H). Only models that anticipated the invaded areas of North America were

721 included. The color pallet is standard for all figure panels.

722 Figure 4. Sum of all suitable areas for Vespa mandarinia in North America derived from

723 binarizing each replicate of selected models (model transfers done with extrapolation) using a

$7245 \%$ threshold. Each replicate predicted the known invaded localities of this hornet.

725 Figure 5. Agreement of areas with extrapolation risk for models of Vespa mandarinia in North

726 America, separated by calibration schemes.

727 Figure 6. Results from simulations of the potential dynamics of invasion of Vespa mandarinia in

728 North America. Dark shades of green show areas that the species reached in a high percentage of

729 scenarios, while light shades of green represent areas reached only rarely by the species. Arrows

730 represent the general path of potential invasion.

731 Figure 7. Representation of potential ecological and economic impacts of an invasion of Vespa 
732 mandarinia. A: honey production (in US dollars) in Mexico and the United States in 2016. B:

733 species richness of the genera Bombus (bumble bees) and Melipona (stingless bees) in North

734 America. The area shaded in gray represents the simulated potential invaded area of Vespa

735 mandarinia in North America obtained with the $50 \mathrm{~km}$ spatial thinning occurrences and PCs as

736 environmental predictors. We used this scenario because is the one that best connects the known

737 invaded areas with the eastern United States. 
Figure 1

Hypothesis of accessible areas (M) and representation of the occurrence records of Vespa mandarinia across its native distribution.

The three panels represent the occurrences left after cleaning $(\mathrm{A})$ and after applying the two thinning approaches (B and $\mathrm{C}$ ). 


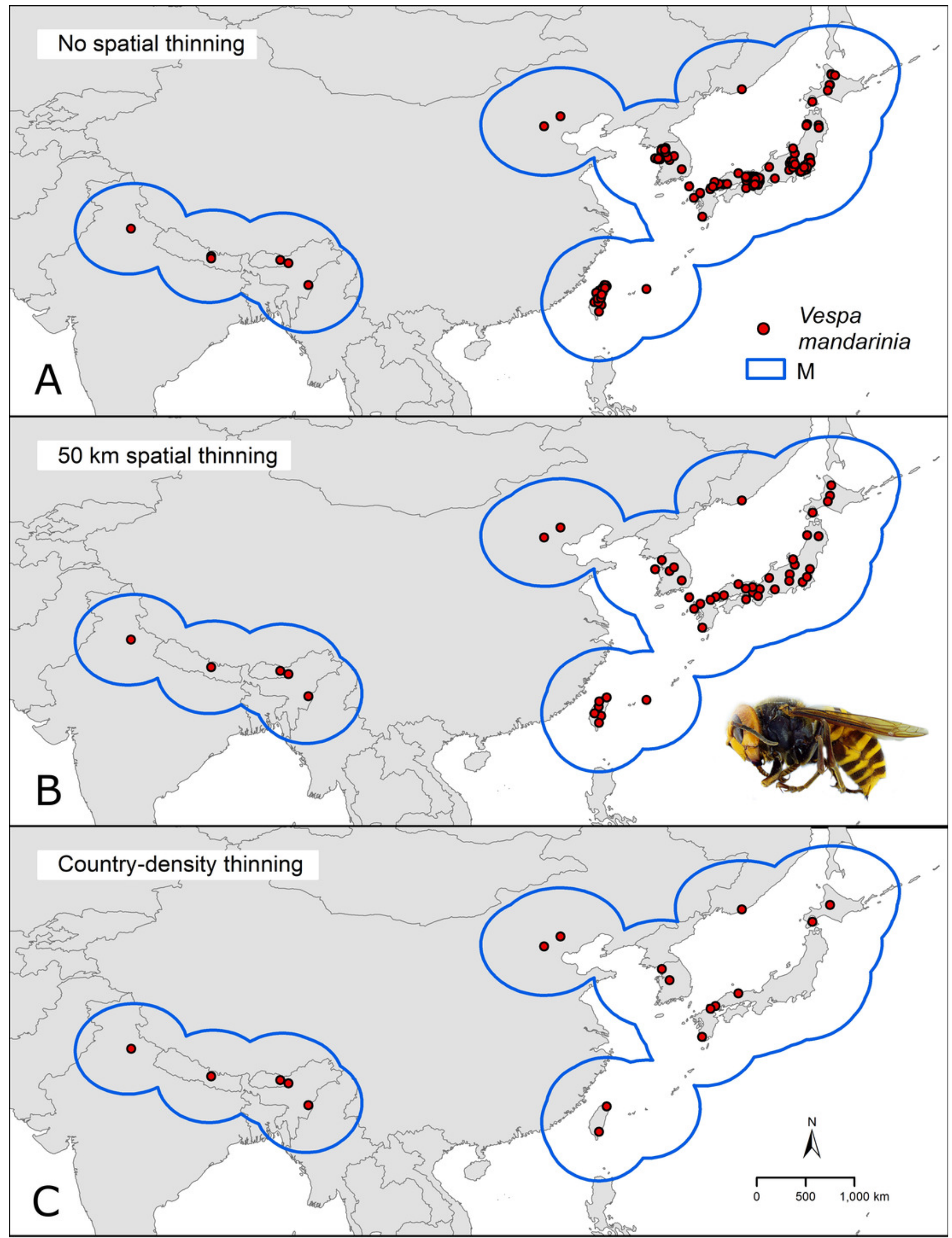

Peer] reviewing PDF | (2020:08:51881:2:0:CHECK 9 Dec 2020) 
Figure 2

Schematic representation of methods used to obtain ecological niche models for Vespa mandarinia.

The aim of the modeling process was to consider the variability resulting from different procedures and methodological decisions made during model calibration.

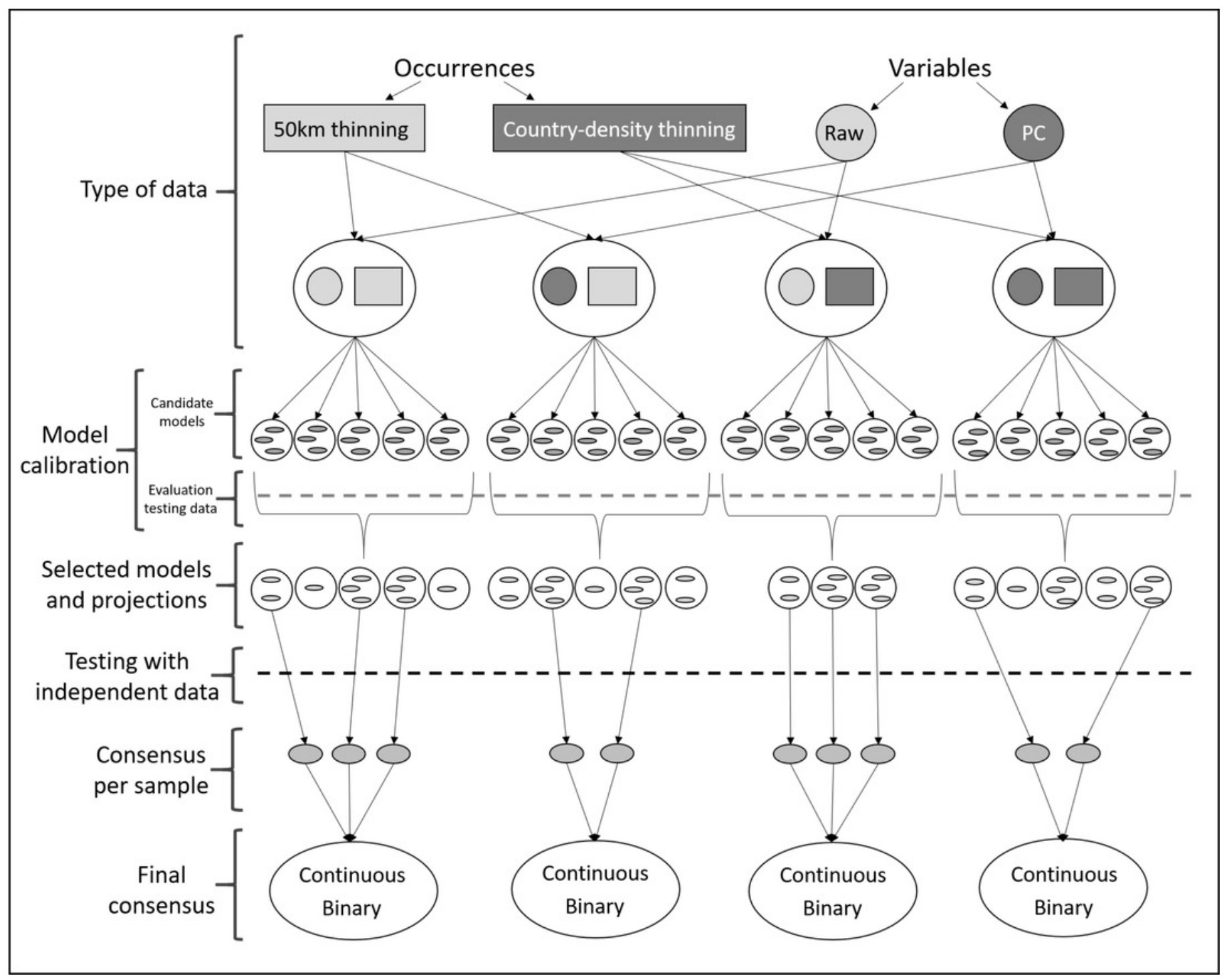


Figure 3

Median of potentially suitable areas for Vespa mandarinia predicted with free extrapolation for different calibration schemes in the calibration area $(A, C, E, G)$ and in North America (B, D, F, H).

Only models that anticipated the invaded areas of North America were included. The color pallet is standard for all figure panels. 


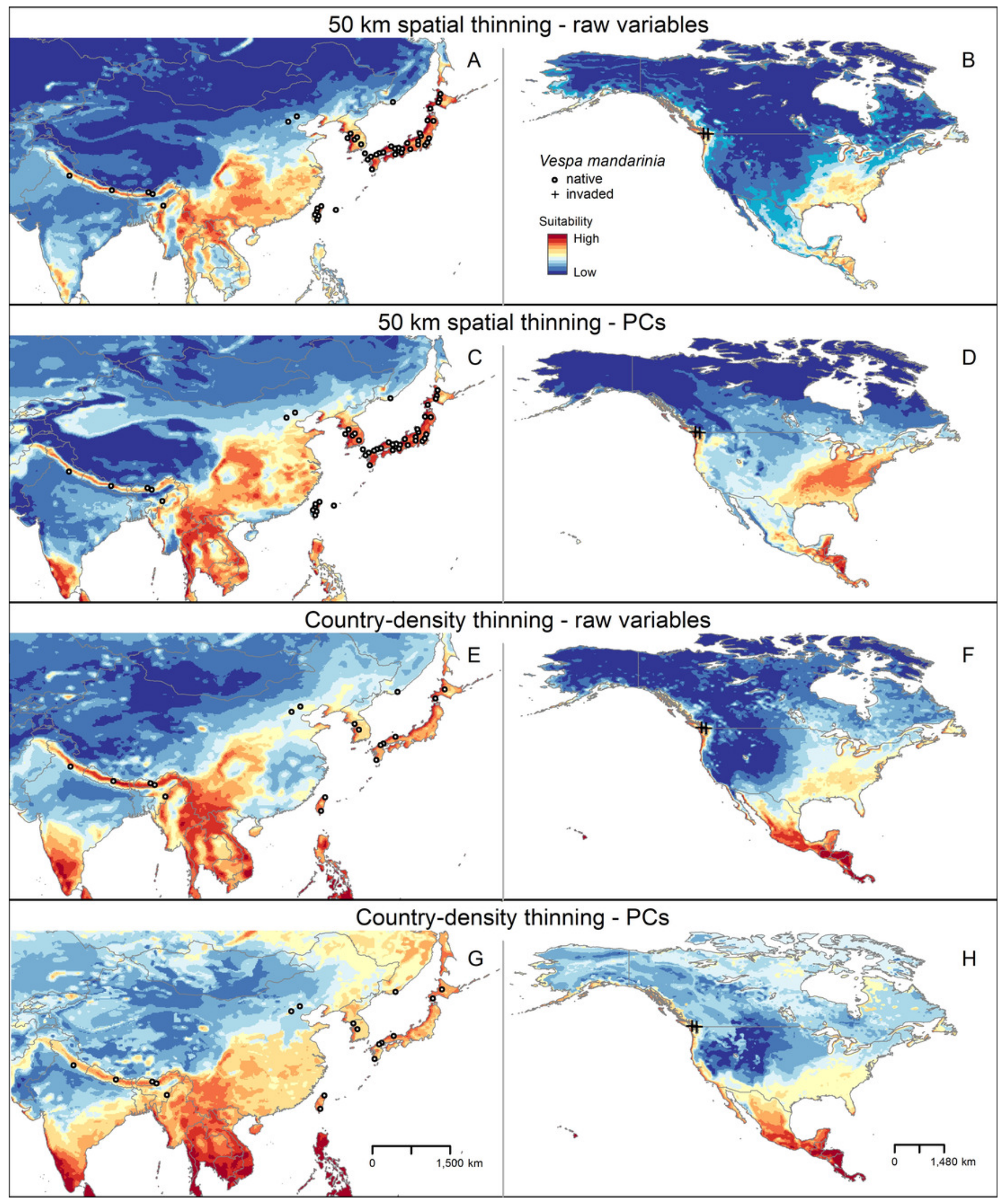




\section{Figure 4}

Sum of all suitable areas for Vespa mandarinia in North America derived from binarizing each replicate of selected models (model transfers done with extrapolation), using a $5 \%$ threshold.

Each replicate predicted the known invaded localities of this hornet.

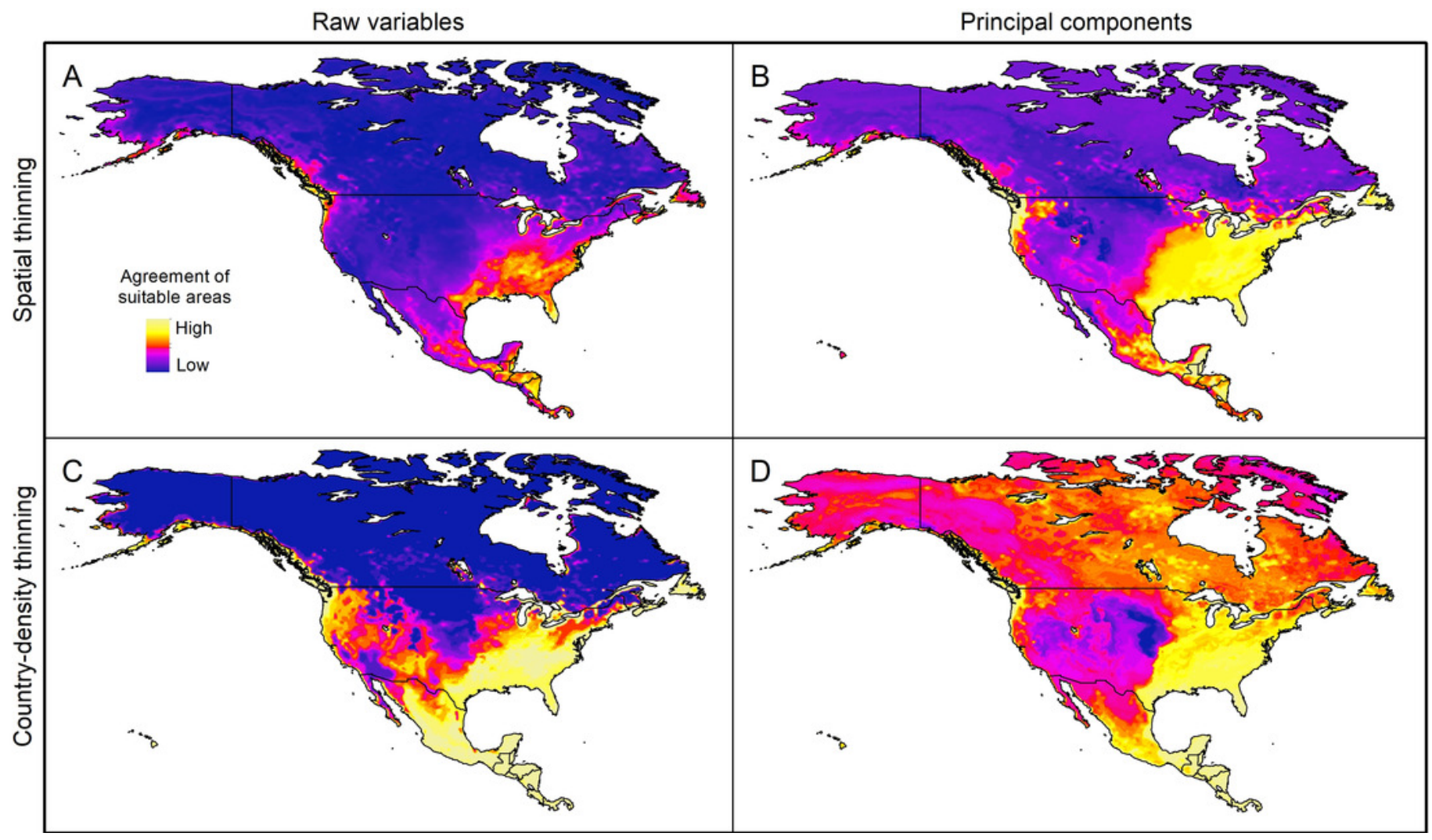


Figure 5

Agreement of areas with extrapolation risk for models of Vespa mandarinia in North America, separated by calibration schemes.

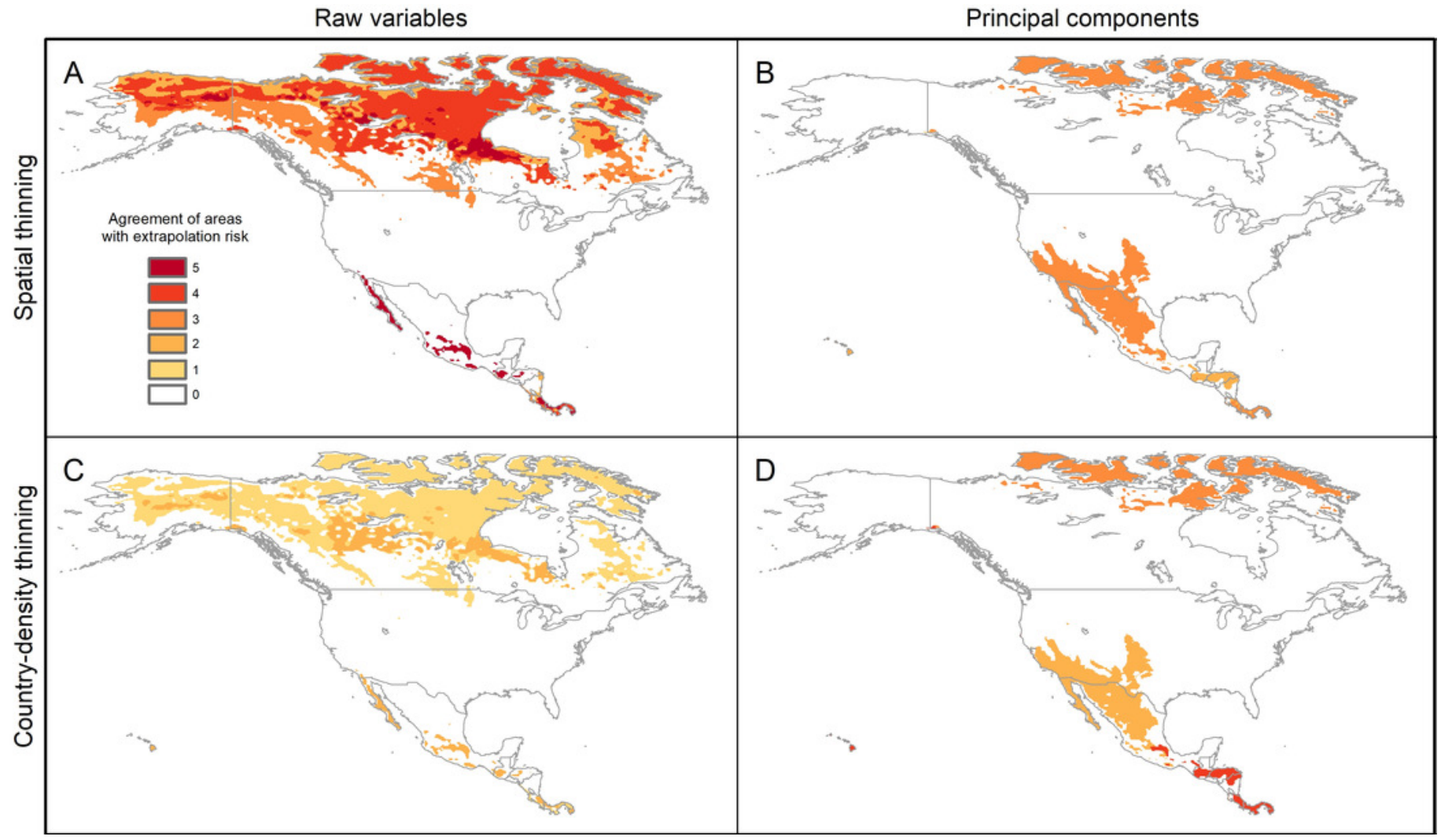


Figure 6

Results from simulations of the potential dynamics of invasion of Vespa mandarinia in North America.

Dark shades of green show areas that the species reached in a high percentage of scenarios, while light shades of green represent areas reached only rarely by the species. Arrows represent the general path of potential invasion.

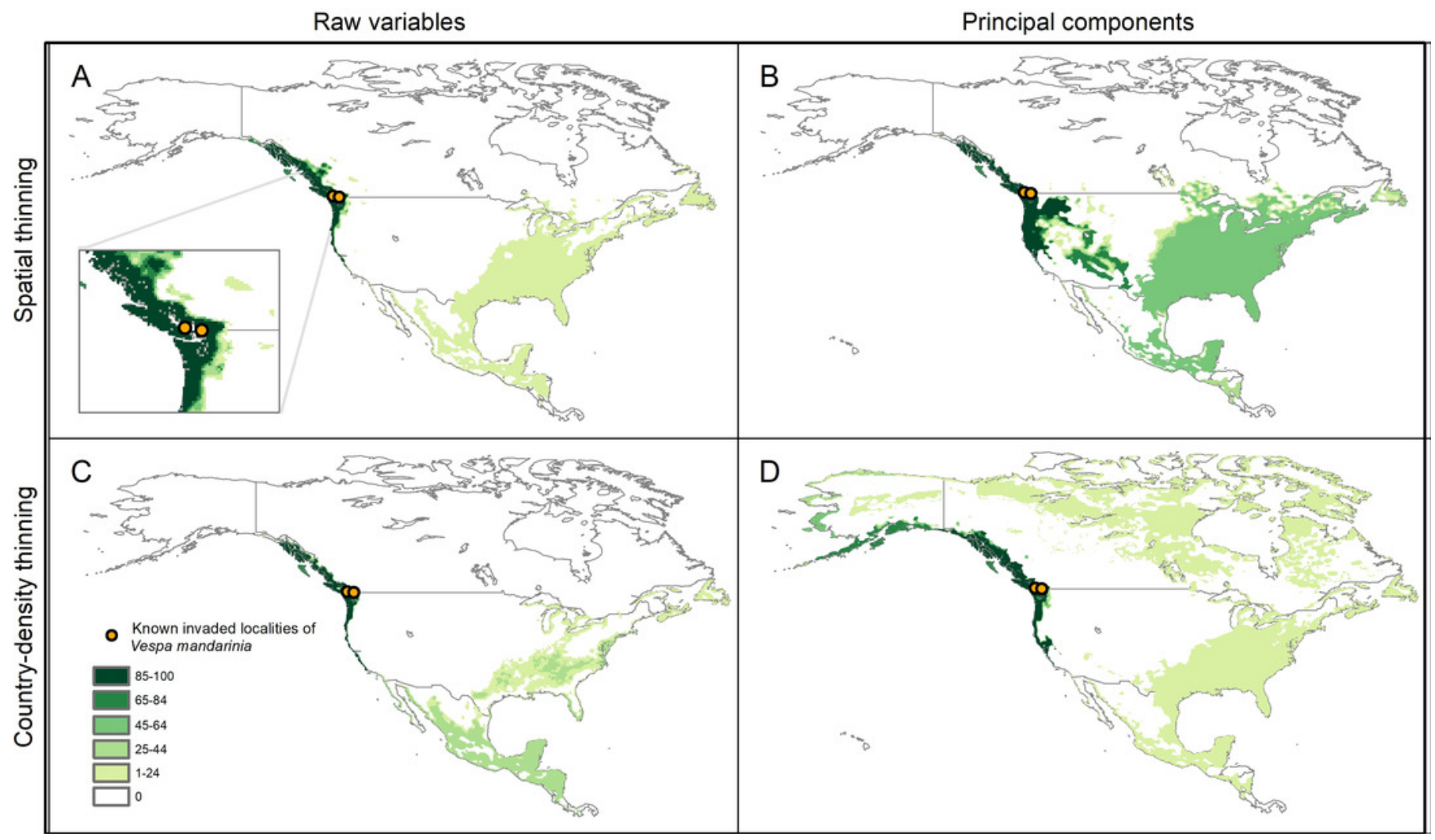




\section{Figure 7}

Representation of potential ecological and economic impacts of an invasion of Vespa mandarinia.

A: honey production (in US dollars) in Mexico and the United States in 2016. B: species

richness of the genera Bombus (bumble bees) and Melipona (stingless bees) in North America. The area shaded in gray represents the simulated potential invaded area of Vespa mandarinia in North America obtained with the $50 \mathrm{~km}$ spatial thinning occurrences and PCs as environmental predictors. We used this scenario because is the one that best connects the known invaded areas with the eastern United States. 


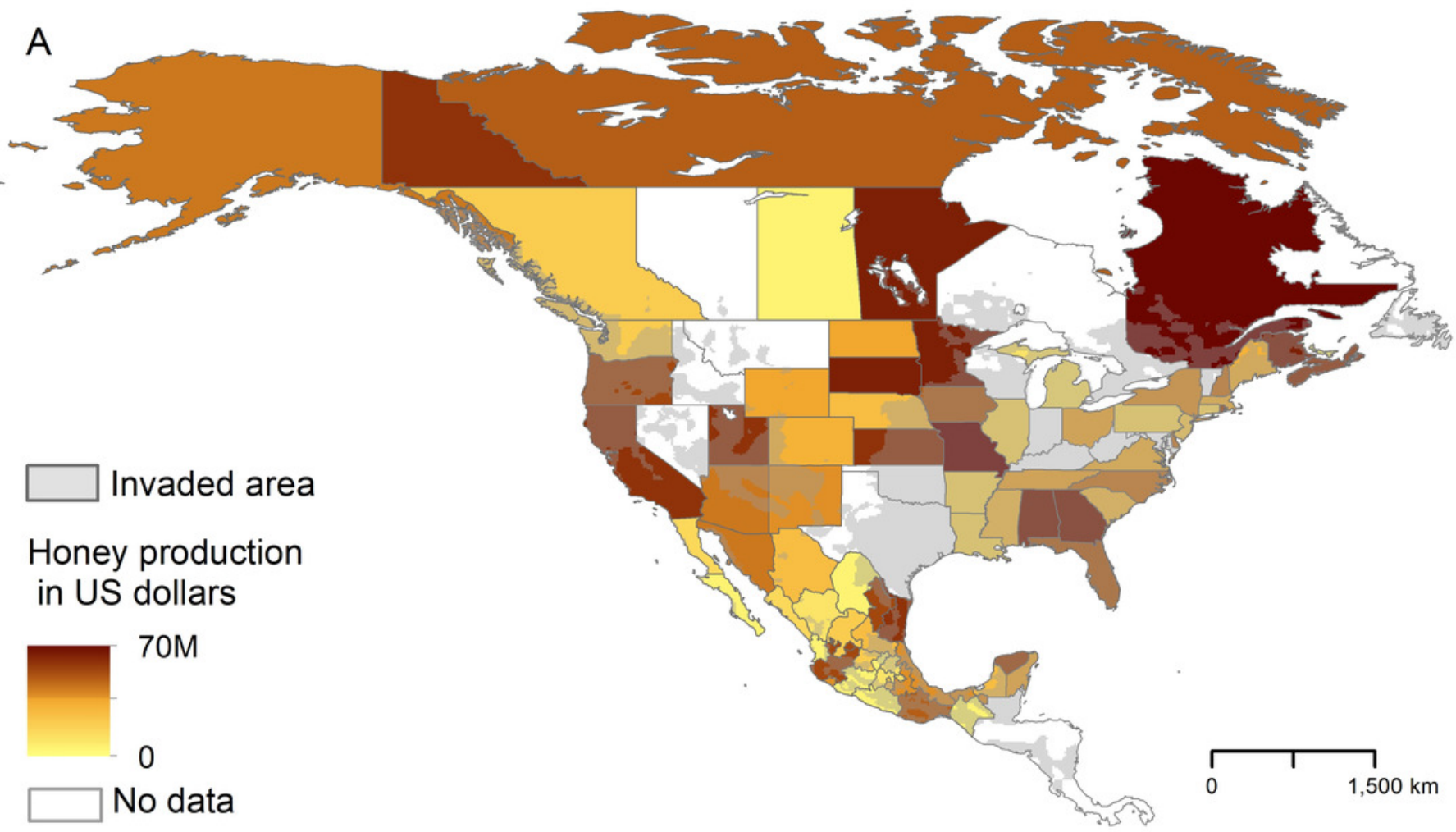

B

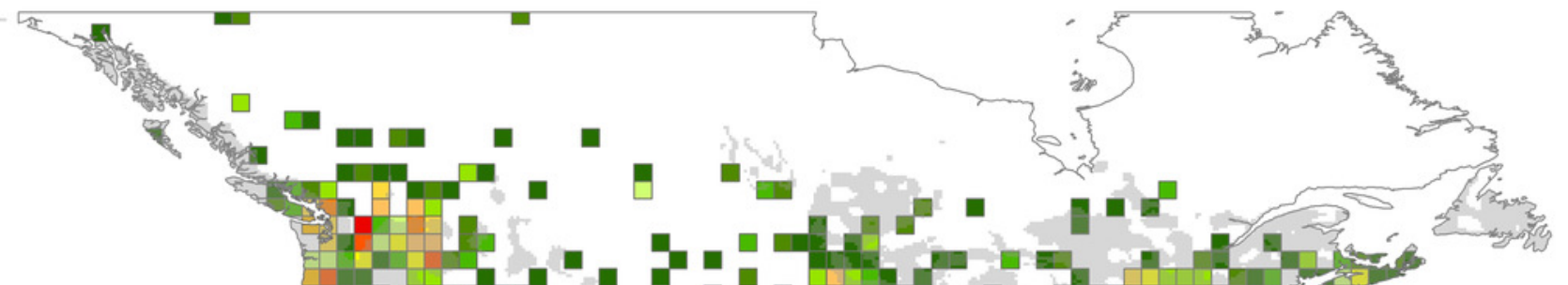

Invaded area

Bombus and Melipona species richness

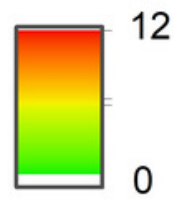

12
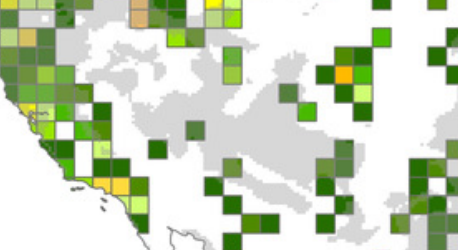

둔돈

음

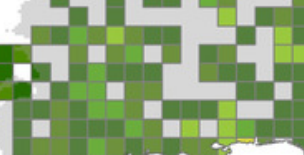




\section{Table $\mathbf{1}$ (on next page)}

Summary of results of ecological niche modeling for Vespa mandarinia, including model calibration, model evaluation, and relevant Maxent settings for models selected after independent testing.

Maxent settings are represented in the columns 'Regularization multiplier,' 'Feature classes,' and 'Variable sets'. The column 'Calibration processes' refers to each of the five calibrations processes that were done with different sets of random points, for every calibration scheme. The variables included in the sets mentioned on this table can be found in Table 1S-2S. E: free extrapolation; EC: extrapolation with clamping; NE: no extrapolation, PCs: principal components. 


\begin{tabular}{|c|c|c|c|c|c|c|}
\hline $\begin{array}{l}\text { Calibration } \\
\text { scheme }\end{array}$ & $\begin{array}{c}\text { Calibration } \\
\text { processes }\end{array}$ & $\begin{array}{l}\text { Models meeting } \\
\text { selection criteria }\end{array}$ & $\begin{array}{l}\text { Models predicting } \\
\text { independent records } \\
(\mathrm{E} ; \mathrm{EC} ; \mathrm{NE})\end{array}$ & $\begin{array}{c}\text { Regularization } \\
\text { multiplier }\end{array}$ & Feature classes & Variable sets \\
\hline \multirow{5}{*}{$\begin{array}{l}\text { Raw variables } \\
\text { and distance } \\
\text { thinned } \\
\text { occurrences }\end{array}$} & 1 & 6 & $8 ; 2 ; 10$ & $0.25 ; 0.5 ; 0.75$ & lq; lqpt & $42 ; 43 ; 50 ; 51 ; 57$ \\
\hline & 2 & 1 & - & - & - & - \\
\hline & 3 & 1 & $6 ; 4 ; 4$ & 0.75 & lqpth & 12 \\
\hline & 4 & 1 & $2 ;-; 1$ & 0.25 & lq & 21 \\
\hline & 5 & 2 & $7 ; 7 ; 13$ & $0.1 ; 0.25$ & lq & 26 \\
\hline \multirow{5}{*}{$\begin{array}{l}\text { PCs and } \\
\text { distance } \\
\text { thinned } \\
\text { occurrences }\end{array}$} & 1 & 4 & $24 ; 18 ; 20$ & 5 & lqph; lqpth & $7 ; 11$ \\
\hline & 2 & 2 & $10 ; 5 ; 5$ & $0.25 ; 0.5$ & qp & 11 \\
\hline & 3 & 4 & $22 ; 23 ; 19$ & $0.1 ; 0.25 ; 0.5 ; 0.75$ & $\mathrm{lp}$ & 11 \\
\hline & 4 & 3 & $9 ; 8 ; 11$ & $0.25 ; 0.5 ; 0.75$ & $\mathrm{qp}$ & 7 \\
\hline & 5 & 6 & $21 ; 21 ; 26$ & $0.1 ; .25 ; 0.5 ; 0.75$ & lqp & $2 ; 9$ \\
\hline \multirow{5}{*}{$\begin{array}{l}\text { Raw variables } \\
\text { and country- } \\
\text { density thinned } \\
\text { occurrences }\end{array}$} & 1 & 1 & $4 ; 4 ; 6$ & 0.1 & lqp & 22 \\
\hline & 2 & 2 & $4 ; 11 ; 8$ & 0.1 & lq; lqp & $5 ; 22$ \\
\hline & 3 & - & - & - & - & - \\
\hline & 4 & 3 & $15 ; 13 ; 16$ & $0.1 ; 2$ & lq; lqph; lqpth & $13 ; 32$ \\
\hline & 5 & - & - & - & - & - \\
\hline \multirow{5}{*}{$\begin{array}{l}\text { PCs and } \\
\text { country-density } \\
\text { thinned } \\
\text { occurrences }\end{array}$} & 1 & 7 & $32 ; 31 ; 32$ & $0.25 ; 0.5 ; 0.7 ; 1$ & lp; lqpt; lqpth & $2 ; 4 ; 5 ; 6 ; 8$ \\
\hline & 2 & 1 & $1 ; 3 ; 1$ & 1 & lqpth & 8 \\
\hline & 3 & 1 & $5 ; 6 ; 7$ & 0.1 & $\mathrm{q}$ & 4 \\
\hline & 4 & 4 & $24 ; 22 ; 18$ & $0.1 ; 0.25 ; 0.5 ; 0.74$ & $\mathrm{lp}$ & 1 \\
\hline & 5 & 2 & $5 ; 7 ; 5$ & 1 & lqp & $1 ; 6$ \\
\hline
\end{tabular}

1 